\title{
WELFARE TRANSITIONS AND ITS CORRELATES AMONG COCOA FARMING HOUSEHOLDS IN NIGERIA
}

\author{
Lawal, J.O'., Omonona, B.T ${ }^{2}$., Oluwatayo, I.B. ${ }^{3}$ and SalmanK.K. ${ }^{2}$ \\ ${ }^{1}$ Economics Section, Cocoa Research Institute of Nigeria, Ibadan, Nigeria \\ ${ }^{2}$ Department of Agricultural Economics, University of Ibadan, Ibadan, Nigeria \\ ${ }^{3}$ Department of Agricultural Economics, University of Limpopo, Polokwane South Africa \\ Email: yemisilawal2003@yahoo.com
}

\begin{abstract}
This study determined the correlates of welfare using panel data collected in heavy and light cocoa seasons through multistage sampling techniques from 366 cocoa farming households. Data collected were subjected to descriptive and Ordered Probit model of analysis using STATA. Welfare categories were based on the relative welfare line constructed from the mean per capita household expenditure for each season. Results revealed that male-headed households were more among the cocoa farming households, with mean age of $54 \pm 12.64$ years, household size of $7 \pm 3.19$ persons, farming experience $28 \pm 14.41$ years and mean age of the cocoa trees were $30 \pm 19.21$ years and this shows that the farmers and their cocoa trees are old, there by affecting the productivity and the welfare of the farmers. The ordered probit result corroborates this results because age of household head ( $p<0.05)$, gender of household head $(p<0.1)$, age of cocoa $(p<0.05)$, poor access to credit ( $p<0.05)$, poor collateral status $(p<0.01)$ and high tax levies $(p<0.05)$ on cocoa production negatively affects welfare of Cocoa Farming Households while literacy $(p<0.1)$, type of land tenure system used on cocoa farm $(p<0.01)$, price increase of produce $(p<0.01)$, good harvest from plantations $(p<0.01)$ and access to extension service $(p<0.1)$ enhanced cocoa farming households' welfare.
\end{abstract}

Keywords: Welfare transition, cocoa seasons, ordered Probit and Nigeria

\section{INTRODUCTION}

Cocoa (Theobroma cacao) is a tropical species with a narrower geographical range than coffee. Cocoa trees grow between $20^{\circ}$ North and South of the equator, majority of production is concentrated at low elevations below $300 \mathrm{~m}$ or 1000 feet and within $10^{\circ}$ North and South of equator (Purseglove, 1968; Ajayi et al, 2010; www.icco.org). Cocoa trees yield well under relatively high temperatures, with maximum and minimum mean annual temperatures of $3032{ }^{\circ} \mathrm{C}$ and $1821{ }^{\circ} \mathrm{C}$, respectively (Lawal and Emaku, 2007; Ajiboye et al., 2015). Cocoa is sensitive to soil water de?ciency and yields are more affected by rainfall than by any other environmental factor (Lawal 
and Omonona, 2014). Cocoa is produced mainly in 14 states of the federation and with a total planted area of 640,000 hectares. The National Cocoa Development Committee (NCDC) made up of the 14 cocoa producing states in the country distributes high yielding cocoa seedlings to farmers, while Cocoa Research Institute of Nigeria (CRIN) contributes in the areas of research needs and development of the crop along the value chain, distributing high yielding, disease resistant and improved varieties to farmers, training of growers in modern agricultural practices as well as in business development skills. Nigeria produces 280,000 metric tons of cocoa (GAIN-USDA, 2011). The south-western part of Nigeria is regarded as the cocoa belt of the country accounting for $70 \%$ of the country's annual production. The Nigerian cocoa year is divided into two harvests, with the main one beginning in October and ending in January; while the light harvesting season usually begins in February and ends in September. Social capital status has been reported to be low among cocoa farming households (Lawal, 2010) and other farming households (Anyio, 2015).

The Cocoa Association of Nigeria projected in September 2012 that the Nigerian cocoa output would rise by $20 \%$ to $336,000 \mathrm{MT}$ from $280,000 \mathrm{MT}$ as new farms had started producing but with the incessant rainfall and flooding of the cocoa farms in the year 2012, there were growing cases of Black pod, a fungal disease that thrives in wet conditions. This adversely affected the yields of cocoa, the prices and the livelihood of $\mathrm{CFHs}$.

The changes in the livelihood of CFHs brought about by change in income and expenditure could lead to changes in their welfare status; which could be a rise or an unchanged situation. These changes are referred to as Transitions in Welfare.

This study found what the determinants of being in the different welfare categories are and the proffer targeted recommendations.

\section{METHODOLOGY}

This study was carried out in the South Western part of Nigeria. The South-West Nigeria consists of six states which are Oyo, Osun, Ogun, Ondo, Lagos and Ekiti. These states fall under the high and medium cocoa producing categories in Nigeria. One state each was selected at random from the two categories. The states lies within latitude $4^{\circ}-14^{\circ} \mathrm{N}$ and longitude $3^{\circ}-14^{\circ} \mathrm{E}$ and exhibit the typical tropical climate of averagely high temperature and high relative humidity.

A multistage sampling technique was used. Following the list of cocoa producing Local Government Areas (LGAs) by the States' Agricultural Development Programmes (ADP), eight local governments were chosen from the states in the first stage proportionate to number of LGAs producing cocoa per state. In the second stage, five villages were randomly selected from each of the chosen LGAs using the ADP list of villages. The last stage involved the random selection of cocoa farmers for interview from the list of cocoa farming households within the villages. This selection was done proportionately to the size of the village population. To give a total of 400 respondents from the study areas. This study made use of two point's data that is data collected during the cocoa onseason/heavy harvest (August-January) and cocoa off-season/light harvest (February-June). After 
the first round of data collection, three hundred and eighty-one (381) of the questionnaire were fit for analysis and recording but after the second round of data collection among the same cocoa farming households that were used in the first round, only three hundred and sixty-six (366) of the household were available for the second round either due to migration, fitness of questionnaire for analysis and total disappearance of respondents. Nineteen (19) respondents were lost due to attrition. Data were subjected to descriptive statistics and ordered probit analysis.

\section{Econometric model}

The dependent variable in this study is the welfare categories which is categorical and ordinal with clear ordering. The categories of welfare are defined as Rise in Welfare and No change in Welfare. These were arrived at based on the welfare level of farming households in the heavy cocoa harvest season defined by the mean per capita expenditure of the household at that time and the level of their welfare still based on the mean per capita expenditure of the household in the light cocoa season. A statistical model which is appropriate to explain the ordinal variations of the welfare changes is ordered Probit (Loke, 2013)

The data collected were subjected to both descriptive and ordered Probit analysis.

The dependent variable also known as the outcome variables in Ordered probit model is characterized as follows:

Rise in Welfare: expenditure of cocoa farming household is greater than the relative welfare line constructed based on the mean per capita household expenditure (MPCHHE) of the household (Apata and Rahji, 2007) in both seasons (those who spent two-third or more of their MPCHHE in both seasons are classified as having Rise in Welfare)

No change in Welfare: expenditure of the cocoa farming household is lower than the relative welfare line constructed based on the mean per capita expenditure of the household in both seasons (those who spent less than two-thirds of their MPCHHE in both season are classified has having No change in Welfare) (NBS, 2005).

The categories are given the score of 2 and 1 which indicates rise and no change in welfare.

The Ordered Probit is usually justified on the basis of a latent variable; variables are not directly observed but are rather inferred from other variables that are observed. It is written as:

$Y^{*}=\beta^{\prime} x+y$.

Where $y^{*}=$ latent measure of welfare categories coded as 2 and $1 ; \beta^{\prime}$ is the vector of estimated parameters and $\mathrm{x}$ is the vector of explanatory variables; $\mathrm{a}$ is the error term.

$y$ is determined from the model as $\mathrm{y}^{*}=2$ (rise) if $\mathrm{y}^{*}<\mathrm{ui}$.

$\mathrm{y}^{*}=1$ (no change) if $u i<\mathrm{y}^{*}$

The maximum likelihood estimates are used to derive the marginal effects of explanatory variables which are derived by differentiation for the respective possibilities. Hence, the marginal effects of factor $x$ on the probability of welfare categories was evaluated in STATA 11. 


\section{RESULTS AND DISCUSSION}

The socio-economic characteristics of the cocoa farming households reveal that majority are maleheaded households with only 10.1 percent headed by female respondents. Also, the most popular form of educational status attained by most cocoa farmers is the secondary education with 36.3 percent. The mean age of the household head is $54 \pm 12.64$ years indicating that the farmers are old and getting out of the active working age which may also affect their welfare. The mean household size of the farmers is $7 \pm 3.19$ persons while the mean year of cocoa farming experience span about $28 \pm 14.41$ years and the mean age of the cocoa trees are $30 \pm 19.21$ years; this shows that the cocoa trees are old, and may also affect the productivity and the welfare of the farmers who own them because the productivity of the trees might have dropped, not yielding as much as the farmer desires and the income accruing from the farm may not be adequate enough to cater for the household size which the farmer has. 
Table 1: Socio-Economic Characteristics of Household Heads

Lawal, Omonona, Oluwatayo \& Salman

Table 1: Socio-Economic Characteristics of Household Heads

\begin{tabular}{|c|c|c|c|}
\hline \multicolumn{2}{|l|}{ Socio-economics } & Frequency & $\%$ \\
\hline \\
\hline \multicolumn{2}{|l|}{ Male } & 326 & 89.1 \\
\hline \multicolumn{2}{|l|}{ Female } & & 10.9 \\
\hline \multicolumn{4}{|l|}{ Education } \\
\hline \multicolumn{2}{|l|}{ No formal education } & 75 & 19.4 \\
\hline \multicolumn{2}{|l|}{ Primary } & 117 & 32.0 \\
\hline \multicolumn{2}{|l|}{ Secondary } & 133 & 36.3 \\
\hline \multicolumn{2}{|l|}{ Tertiary } & 41 & 11.2 \\
\hline \multicolumn{4}{|c|}{ Age of Household Head MEAN=54 } \\
\hline \multicolumn{2}{|c|}{$25-35$} & 25 & 6.8 \\
\hline \multicolumn{2}{|l|}{$36-45$} & 89 & 24.3 \\
\hline \multicolumn{2}{|l|}{$46-55$} & 90 & 24.6 \\
\hline \multicolumn{2}{|l|}{$56-65$} & 100 & 27.3 \\
\hline \multicolumn{2}{|l|}{$66-75$} & 52 & 14.2 \\
\hline \multicolumn{2}{|l|}{$>75$} & 10 & 2.7 \\
\hline \multicolumn{4}{|c|}{$\begin{array}{ll}\text { Household Size } & \text { MEAN }\end{array}$} \\
\hline & 86 & 23.5 \\
\hline \multicolumn{2}{|l|}{$6-10$} & 229 & 62.6 \\
\hline \multicolumn{2}{|l|}{$11-15$} & 25 & 6.8 \\
\hline \multicolumn{2}{|l|}{$>15$} & 26 & 7.1 \\
\hline \multicolumn{4}{|c|}{ Years of cocoa farming experience $M E A N=28$} \\
\hline \multicolumn{2}{|c|}{$1-10$} & 45 & 12.3 \\
\hline \multicolumn{2}{|l|}{$11-20$} & 97 & 26.5 \\
\hline \multicolumn{2}{|l|}{$21-30$} & 92 & 25.1 \\
\hline \multicolumn{2}{|l|}{$31-40$} & 66 & 18.0 \\
\hline \multicolumn{2}{|l|}{$41-50$} & 49 & 13.5 \\
\hline \multicolumn{2}{|l|}{$51-60$} & 10 & 2.7 \\
\hline \multicolumn{4}{|l|}{ Age of cocoa MEAN=30 } \\
\hline $1-10$ & & 65 & 17.8 \\
\hline $11-20$ & & 77 & 21.0 \\
\hline $21-30$ & & 70 & 19.1 \\
\hline $31-40$ & & 50 & 13.7 \\
\hline $41-50$ & & 55 & 15.0 \\
\hline $51-60$ & & 24 & 6.50 \\
\hline$>60$ & & 25 & 6.80 \\
\hline
\end{tabular}

Source: Field survey data 2013/2014 


\section{Welfare Transition Matrix}

The mobility of cocoa farming households based on their expenditures can be best described using the Welfare Transition Matrices (WTM). Hence, the WTM between the welfare groups was constructed for the two periods under studied based on the respective welfare classification (use of the MPCHHE) for each period. The welfare transition matrix (Table 2) was arrived at by synchronizing the welfare status of each cocoa farming household from the heavy season to the light season.

The welfare transition matrix shows the movement of cocoa farming households in between the cocoa seasons. This shows that in the heavy season $34.15 \%, 34.15 \%$ and $31.70 \%$ were in the low, medium and high welfare groups respectively while in the light season, $21.31 \%, 51.64 \%$ and $27.05 \%$ were in the welfare groups respectively. This result shows the transition in welfare from low to medium or high as rise in welfare while those that remained in the low, medium and high groups in both seasons as not having changes in welfare status.

Table 2: Welfare Transition matrix of cocoa farming households in both seasons

\begin{tabular}{llccc}
\hline Light/Heavy & LOW & MEDIUM & HIGH & TOTAL \\
\hline LOW & $59(16.21)$ & $65(17.76)$ & $1(0.27)$ & $125(34.15)$ \\
MEDIUM & $13(3.55)$ & $98(26.78)$ & $14(3.78)$ & $125(34.15)$ \\
HIGH & $6(1.65)$ & $26(7.10)$ & $84(22.95)$ & $116(31.70)$ \\
TOTAL & $78(21.31)$ & $189(51.64)$ & $99(27.05)$ & 366 \\
\hline
\end{tabular}

Sources: Field Survey 2013/2014 seasons

\section{CORRELATES OF WELFARE TRANSITION}

A number of variables were tested for significance as determinants of rise and no change in welfare among cocoa farming households; only ten of the variables were significant for rise in welfare while nine were significant for no change in welfare at different levels of probability. The statistics shows the likelihood ratio of -208.301 and Pseudo R2 for Ordered Probit of 0.2077 indicates that the model fits well and is significant at 1 percent level of probability.

The positive coefficient estimates as depicted in table 3 shows that literacy $(p<0.1)$, type of land tenure system used on cocoa farm $(p<0.01)$, price increase of produce $(p<0.01)$, access to extension service $(p<0.1)$ and good harvest from plantations $(p<0.01)$ drives/ increases the Rise in welfare among cocoa farming households. While on the other hand, the negative coefficient Estimates such as Age of household head $(p<0.05)$, gender of household head $(p<0.1)$, age of cocoa $(p<0.05)$, poor access to credit $(p<0.05)$, poor collateral status $(p<$ $0.01)$ and high tax levies $(p<0.05)$ oncocoa production negatively affects rise in welfare among CFHs. 
Table 3: Marginal Effect estimates for Ordered Probit (Rise in Welfare)

\begin{tabular}{|c|c|c|c|c|}
\hline variables | & $d y / d x$ & Std. Err. & $z$ & $\mathrm{P}>|\mathrm{z}|$ \\
\hline Age & $-.0023^{* *}$ & .00116 & -1.97 & 0.048 \\
\hline Gender & $-.1133^{*}$ & .06506 & -1.74 & 0.081 \\
\hline Literacy & $.0470^{*}$ & .02803 & 1.67 & 0.095 \\
\hline Agecoc & $-.0016^{\star *}$ & .00081 & -2.01 & 0.044 \\
\hline Farmsize & .00022 & .00227 & 0.10 & 0.924 \\
\hline Assomem & -.0039 & .03396 & -0.12 & 0.908 \\
\hline Poaccredt & $-.0639^{* *}$ & .03155 & -2.03 & 0.043 \\
\hline Landten & $.0927^{* * *}$ & .02469 & 3.76 & 0.000 \\
\hline Pric increase & $.0820^{* * *}$ & .02672 & 3.07 & 0.002 \\
\hline Poorcolater & $-.1068^{* * *}$ & .03476 & -3.07 & 0.002 \\
\hline Goodharvt & $.1407^{\star \star \star}$ & .03338 & 4.22 & 0.000 \\
\hline High tax levies & s-. $0555^{\star *}$ & .02733 & -2.03 & 0.042 \\
\hline Remittance & .0418 & .05585 & 0.75 & 0.454 \\
\hline Extension & $.0535^{\star *}$ & .0287 & 1.86 & 0.062 \\
\hline Illdeath & .0164 & .0369 & 0.44 & 0.657 \\
\hline Gdroadtomkt & -.0311 & .02838 & -1.10 & 0.273 \\
\hline
\end{tabular}

Source: Printout of Ordered Probit $\quad$ *Significant at 10\%; ** Significant at $5 \% ;{ }^{* * *}$ Significant at $1 \%$

The Determinants of No Change in Welfare status among cocoa farming households in South-west, Nigeria

The variables with negative coefficient estimates: literacy $(p<0.1)$, land tenure $(p<0.05)$, good harvest from plantations $(p<0.01)$, and access to extension services $(p<0.5)$ have shown as the determinants that can help maintain high welfare status of farming households for the better instead of just remaining stagnant, but variables with positive coefficient estimates like age of household head $(p<0.1)$, poor access to credit $(p<0.1)$, poor collateral $(p<0.01)$ and high tax levies $(p<0.1)$ has shown as the factors that promote low welfare status and no changes in welfare among cocoa farming households in South-west, Nigeria. 
Table 4: Marginal effect estimates for Ordered Probit (No Change in Welfare)

\begin{tabular}{lcccc} 
variables & $\mathrm{dy} / \mathrm{dx}$ & Std. Err. & $\mathrm{z}$ & $\mathrm{P}>|\mathrm{z}|$ \\
\hline Age & $.0013^{*}$ & .00076 & 1.81 & 0.071 \\
Gender & .0868 & .05716 & 1.52 & 0.129 \\
Literacy & $-.0255^{*}$ & .01506 & -1.70 & 0.090 \\
Agecocoa & $.0010^{*}$ & .00053 & 1.86 & 0.063 \\
Farmsize & -.0001 & .00136 & -0.10 & 0.924 \\
Assome & .0024 & .02058 & 0.11 & 0.909 \\
Pooracret & $.0379^{*}$ & .0201 & 1.88 & 0.060 \\
Landten & $-.0316^{* *}$ & .0157 & -2.02 & 0.044 \\
Pric increase & -.0185 & .0187 & -0.99 & 0.322 \\
Porcolatera & $.0642^{* * *}$ & .0245 & 2.62 & 0.009 \\
Goodharvest & $-.0660^{* * *}$ & .0229 & -2.89 & 0.004 \\
High tax levies & $.0318^{*}$ & .0165 & 1.93 & 0.054 \\
Remitance & -.0286 & .0422 & -0.68 & 0.498 \\
Extension & $-.0250^{* *}$ & .0118 & -2.12 & 0.034 \\
Illdeath & -.0097 & .0218 & -0.45 & 0.655 \\
Gdroadmkt & .0181 & .0165 & 1.10 & 0.273 \\
\hline
\end{tabular}

Source: Printout of Ordered Probit * Significant at 10\%; * Significant at 5\%; *** Significant at $1 \%$

\section{CONCLUSION AND RECOMMENDATIONS}

This study concludes that the welfare of cocoa farming household transited between the seasons and there were several correlates of welfare transitions (both rise in welfare and no change) among cocoa farming households in south-west, Nigeria. This study therefore recommends that for expected rise in welfare and exit of cocoa farming households from vicious cycle of poverty;

Newly developed cocoa varieties which are disease resistant and climate change tolerant should be planted to ensure increased /good harvests;

Younger men and women should be encouraged into cocoa farming for better management of the plantations and increased production areas;

Government should ensure that pro-cocoa farmers policies are enacted in the areas of lower tax levies, price increase and stabilization, good land tenure system and adequate access to credit;

Government should ensure that farmers can have better access to credit through their social capital; Research and extension officers should be mandated to train and give feedback on new technologies to farmers for adoption to improve their productivity. 


\section{REFERENCES}

Ajayi I. R., Afolabi M.O., Ogunbodede E.F. and Sunday A.G(2010). Modelling Rainfall as a Constraining Factor for Cocoa Yield in Ondo State.American Journal of Scientific and Industrial Research, vol1(2): 127-134 ISSN: 2153 - 649X Doi:10.5251/Ajsir.2010.1.2.127.134.

Ajiboye, G.A., Jaiyeoba, J.O., Olaniyan, J.O. and A.O. Olaiya (2015). The characteristics and suitability of Soils of some major Cocoa growing areas of Nigeria: Etung LGA Cross-Rivers State. Agrosearch 15(1):101-116.

Apata, T.G and Rahji, M.A.Y. (2007). Poverty and Poverty status in Oil Producing Communities of Ondo State. Agrosearch 9(1\&2): 1-9

Anyio, C.O. (2015). Effect of Social Capital on access to micro-credit among rural farming households in Abia, Nigeria. Agrosearch15(1):59-75

Baulch, B. and N. McCulloch. 2002. Being Poor and Becoming Poor: Poverty Status and Poverty Transitions in Rural Pakistan. doi: 10.1177/002190960203700208 Journal of Asian and African Studies. 37 (2): 168-185.

CRIN (2012.) Updated version of NCDC REPORT

Fingleton, B., 1998. Specification and testing of Markov Chain Models: An application to convergence in the European Union. Oxford Bull. Econ. Stat., 59(3): 385-403.

GAIN REPORT agriexchange.apeda.gov.in/marketreport/Reports/Nigeria_cocoa_product Ni11018 http://gain.fas.usda.gov/

Lawal, J.O. and L.A. Emaku (2007). Evaluation of the effects of Climatic changes on Cocoa Production in Nigeria: Cocoa Research Institute of Nigeria CRIN a case study. African Crop Science Conference Proceeding 8: 423-426.

Lawal , J.O., B.T. Omonona, O.I.Y. Ajani and A.O. (2009). Effects of Social Capital on Credit Access among Cocoa Farming Households in Osun State, Nigeria. Agricultural Journal. 4 (4): 184-191

Lawal, J. O. and Omonona, B. T. (2014). The effects of rainfall and other weather parameters on cocoa production in Nigeria. Comunicata Scientiae 5(4): 518-523.

Loke, Y.J (2013). Household's Preparedness for Income Shock. Being paper presented at Singapore Economic Review Conference 6-8August, 2013.

NBS REPORT (2005). Poverty and The Middle Class: The Nigerian Case National Bureau of Statistics (NBS) working paper IV.

NCDC, (2010) Report of Cocoa Survey of Cocoa Growing States of Nigeria.

Purseglove, J.W (1968) Tropical Crops; Dicotyledons Volumes 1 and 2 London: Longman. 